\title{
Framework for Assessing Resilience in the Communication Networks of AEC Teams
}

\author{
Bryan Franz ${ }^{1 *}$, Robert Leicht ${ }^{2}$, and Katherine Maslak ${ }^{3}$
}

\begin{abstract}
Architecture, engineering and construction (AEC) teams experience frequent changes in membership when delivering a project. While some of these changes are planned (e.g. phased involvement, role reassignment), others are unexpected (e.g. career change, sudden downsizing). Poorly planned or unexpected changes in membership can bring communication to a standstill and impair a team's ability to deliver a successful project. By examining literature from civil engineering, as well as recent studies on network and team science, we propose a conceptual framework that places the formation, disruption and recovery cycle of communication networks in the context of a construction project. The purpose of this framework is to gain a better understanding of resilient communication networks at the project-level. To demonstrate the potential of this framework, email data was collected from the construction manager on an in-progress project that experienced an unexpected departure of their onsite project engineer. A week-byweek content and network analysis was performed for a period of one month to examine the impact of this change in team membership. The results suggest that the disruption in their communication network, measured as between a 40 to $50 \%$ loss in density, average degree and centralization following the departure of the Project Engineer, closely resembled the pattern of loss and recovery illustrated by the resilience triangle. Through discussion, the implications of these results at the project- and firm-level impacts are explored. Specifically, the framework demonstrated potential in forecasting vulnerability in a communication network by examining structural properties, such as high betweenness centrality relative to other members. However, we further that additional studies are needed to fully understand the dynamics and long-term benefits of more resilient communication networks, particularly as they relate to demographics and skillset of team members and the role of integrated delivery methods in promoting more robust networks.
\end{abstract}

\section{Keywords}

Social network analysis, SNA, project performance, robustness, rapidity

\footnotetext{
${ }^{1}$ M.E. Rinker, Sr. School of Construction Management, University of Florida, Gainesville, FL, email: bfranz@ufl.edu (corresponding author)

${ }_{2}^{2}$ Penn State University, University Park, PA: rmleicht@engr.psu.edu

3 M.E. Rinker, Sr. School of Construction Management, University of Florida, Gainesville, FL: kmaslak@ufl.edu
} 


\section{Introduction}

Information flow is critical to successful project delivery. Multidisciplinary teams of architects, engineers and contractors on construction projects have been described as "information processing" systems (Jin and Levitt 1996). Under this view, individual team members process information by sending and receiving messages along specific lines of communication. The pattern of contact created by the flow of those messages over time forms a communication network (Monge and Contractor 2013). The changes in team composition and structure (e.g. phased involvement, role reassignment) that occur with some regularity on construction projects threaten to disrupt these networks. Network disruptions limit information flow and impair the team's ability to plan and deliver a successful project. The question for AEC project teams, then, is how to form and maintain effective communication networks that are resilient to these types of disruption? The purpose of this research is to present a conceptual framework for answering that question by organizing literature on communication networks, team composition, and resilience. Resilience in this context is taken to mean the ability of a communication network to resist or minimize the negative consequences of disruptions, and to recover quickly from those disruptions (Bruneau et al. 2003).

\section{Background}

Communication networks are particularly relevant in the context of AEC project teams because of the presence of both formalized and emergent patterns of information exchange. Contract arrangements signed at the very beginning of the project mandate a certain formality, frequency and structure for communication among team members. Over time, the construction industry has refined a set of communication processes and protocols (e.g. organizational charts, standard weekly owner-architect-contractor meetings) that support these arrangements. However, as the project advances, a new pattern of communication often emerges by necessity to ensure that the right type of information is being exchanged at the right time with the right person (Javernick-Will et al. 2010). Additionally, the behavioral and personality characteristics of individuals influence their level of engagement in various types of networks, including communication networks (Chinowski et al. 2017). Macomber and Howell (2003) even characterize construction and engineering projects as a "network of commitments," rather than a network of tasks or activities. These overlapping layers of structure for how teams communicate have not been widely explored, despite the substantial potential for conflict that may undermine the flow of information necessary for project success.

For the past two decades, the construction industry has been under pressure to improve its project delivery process to meet increasing client demands for higher quality products and services with lower times to market. Specifically, the industry has been criticized for its extreme fragmentation of trades and engineering disciplines, adversarial culture and reluctance to embrace new technologies (Latham 1994, Egan 1998). Thus, there are ongoing efforts that include improving process integration that reduces rework and design errors (Dainty et al. 2001), developing high performance teams that operate more collaboratively (Mollaoglu-Korkmaz et al. 2011, Di Marco and Taylor 2011) and to exploring longterm alliances through public-private partnerships (PPP) or integrated project delivery (IPD) (Lahdenperä 2012, El Asmar et al. 2013). Effective communication is at the heart of each of these efforts and empirical research has suggested that project success is influenced by the strength of communication channels (Bowen and Edwards 1996, Phua and Rowlinson 2004).

\section{Defining Resilience Communication Networks}

Resilience is the ability of a system to mitigate hazards, contain the effects of disasters when they occur, and carry out recovery activities in ways that minimize disruption and mitigate the effects of future disasters (Bruneau et al. 2003). In the wakes of Hurricanes Katrina in 2005 and Sandy in 2012, the resilience of physical infrastructure systems, including bridges, dams and power distribution 
Figure 1: Resilience triangle for a communication network

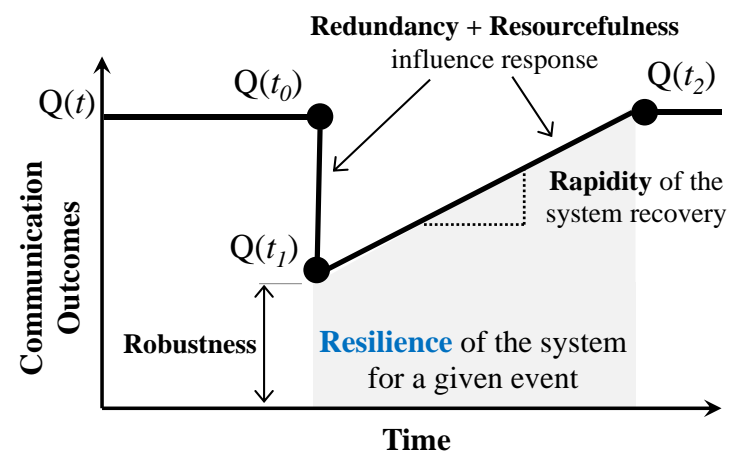

grids, became a prominent topic of research. Resilience is now a common design objective and major requirement in civil and engineering projects performed by the U.S. Army Corps of Engineers and the General Services Admiration. However, outside of infrastructure applications, resilience can be a confusing term. There has been widespread debate about how resilience is measured, much of which stems from differences in how it is conceptualized. In economics, ecology, psychology and organizational science literature, there is little agreement as to whether resilience is a property of the system (Gunderson 2000), a process (Masten 2001) or the capacity of an individual (Youssef and Luthans 2007). Each of these fields of study conceptualizes resilience within their own context, making it challenging to compare resilience across domains. This lack of convergence is at least partly attributable to the dynamic nature of the systems being studied (Walker et al. 2004, Manyena 2006).

Unlike physical infrastructure, the capacity of social systems is always changing, making it difficult to design resilience into that system. In an effort to bridge between theories of resilience found in engineering and those in social sciences, we consider resilience as an emergent property of what the system does, rather than a static property the system has (Park et al. 2013). This means that the resilience of a communication network cannot be determined by examining individual nodes or ties but can only be understood in how the network performs in its response to disruption. This suggests that, at a given point in time, a communication network has an emergent resilience to a disruptive event that is a function of the structural properties of the network, such as centralization, cohesion and density, as well as node-level attributes.

To understand how a system responds to disruption, four properties of resiliencerobustness, rapidity, redundancy and resourcefulness - were first identified by Bruneau et al. (2003) and later mathematically expressed by Cimellaro et al. (2010). Taken together, these properties completely describe a system's resilience to disruption. Figure 1 graphically depicts these properties of resilience alongside the pattern of loss and restoration following a disruptive event, referred to as the "resilience triangle" (Bruneau et al. 2003). The vertical axis in this figure represents performance of the system. When applied to the social system of communication networks, where their purpose is to enable information exchange, the function $\mathrm{Q}(t)$ is used to represent the team's communication outcomes over time.

After a team is procured, the members begin forming network ties, first according to the formal structure offered by the project delivery system, then informally, based on personalities and as necessary to make progress on the project. At some point, the team reaches an optimal level of communication, $\mathrm{Q}\left(t_{0}\right)$. Inevitably, a disruptive event, such as the transitioning away of a senior team member occurs, and the network loses some of its connectivity. Reduced connectivity leads to a decrease in communication. The impact may be instantaneous but may also degrade gradually over time until the point of lowest communication, $\mathrm{Q}\left(t_{1}\right)$, is reached. The communication that remains, i.e., the difference in communication outcomes between $\mathrm{Q}\left(\mathrm{t}_{0}\right)$ and $\mathrm{Q}\left(t_{1}\right)$, is the robustness of the network to that disruptive event. Rapidity is the average rate of recovery occurring between $t_{1}$ and $t_{2}$ to restore communication to either pre-disruption levels, such that $\mathrm{Q}\left(t_{2}\right)=\mathrm{Q}\left(t_{0}\right)$, or another, new optimal level. Both the structural redundancy in the network and the resourcefulness of individual team members can influence how the system responds under stress and may be considered antecedents of robustness and rapidity. For example, the presence of structurally equivalent relationships among multiple team members adds 
redundancy to the network that may enable the team to recover faster from a loss. Similarly, individuals and organizations vary in their response to crisis, and some are more resourceful than others in forming new communication ties to restore connectivity. Resilience itself is typically quantified as the integral of $\mathrm{Q}(t)$ taken between the time of disruption, $t_{1}$, and time of full recovery, $t_{2}$. Therefore, a resilient communication network for AEC teams is one that retains usefulness in the face of disruptions and one that quickly restores lost communication pathways.

\section{Compositional Change Construction Projects}

Most empirical studies on project delivery systems operate under the assumption that project management teams are static - that once selected, individuals are bound together contractually to remain in their pre-assigned, formal roles for the duration of the project. In reality, there are both planned and unplanned changes in the composition of project teams that are viewed as having a negative impact on project performance (Chua et al. 1999, Parker and Skitmore 2004). Planned changes, such as retirements, promotions and the transitions that occur during project phase changes (e.g. from design to construction) typically have less severe consequences. Since project teams may have advanced notice of these events, they can implement succession planning (Raiden et al. 2004) to capture knowledge from the departing team member and to train their successor. Unplanned changes may include individuals leaving to pursue a better career opportunity, individuals suffering jobsite injuries and firms going out business mid-project. These changes are viewed as turnover and give the project team little time to prepare and respond. In network science, the coming and going of individuals is often referred to as "churn." There is evidence that churn in the composition of project teams has a negative influence on performance (Shaw et al. 2005, Wolf et al. 2009, Sasovova et al. 2010), in part due to the structural holes created in the network that take time to repair (Cummings and Cross 2003, Balkundi et al. 2007).

Certain network structures are advantageous for minimizing the negative effects of churn or other changes in composition (Zaheer et al. 2005). In studies of physical communication networks, such as the World Wide Web, authors find they are very robust to random node removal (Albert et al. 2000, Broder et al. 2000). In other words, these networks maintain a consistent level of service despite the removal of nodes in the network at random. However, when nodes with the highest degrees are removed, the networks rapidly degrade (Newman et al. 2002). This is analogous to AEC project teams, where certain members, such as project managers and superintendents, have centralized roles and are expected to be highly connected. How the communication network responds to any planned or unplanned changes in these high degree roles may, similarly to physical networks, lead to an understanding of resilience in social systems.

\section{Team Composition and Network Structure}

Another important aspect of network response is time dependency. That is to say, the network structure in the present is dependent on the arrangement of nodes and ties in the past. For AEC projects, this arrangement is influenced by the team's composition. A team's composition refers to the surface- and deep-level demographics of all members. Surface-level demographics are readily observable or inferable traits such as age, gender, education, tenure and functional roles of individuals (Horwitz and Horwitz 2007), while deep-level demographics are less obvious and may only become apparent after repeated interactions, such as an individual's knowledge, skills and abilities (Devine and Phillips 2001, Stewart 2006).

A fundamental question in network science is how the demographics of an individual affect their position in the network. One of the main determinants of emergent network structures is the theory of homophily. Perhaps best expressed with the phrase "birds of feather flock together," homophily states that individuals will form network ties with others who are similar. These similarities may include age, gender, education or any number of other demographic attributes (McPherson and Smith-Lovin 1987). Authors hypothesize that homophily reduces physiological discomfort (Heider 1958) and potential areas of 
relationship conflict brought about by physical differences (Sherif 1958). Taken to the extreme, Lau and Murnighan (1998) argue that demographic diversity plays a significant role in how teams organize. They cite the presence of "fault lines" that tend to form along one or more surface-level demographic attributes (e.g. age, education) and fragment a team into multiple subgroups. Currently, the construction industry is in a state of transition. The workforce is becoming more diverse, with greater participation from young people, women and minorities (Briscoe 2005, Menches and Abraham 2007), making homophily a particularly relevant theory for understanding with whom the next generation of project managers and engineers will choose to communicate.

Another theory on network emergence comes from the perspective of social exchange and resource dependency. Beginning with Benson (1975), who defined inter-organizational networks as a political economy, where resources determined a firm's position in the network, exchange theory has successfully been applied to the study of health care delivery (Provan and Milward 1995), corporate leadership (Mizruchi 1996) and alliancing (Larson 1992). The theory itself provides two conditions that are necessary for a communication relation to emerge: (1) there is a discrepancy in resource needs between two individuals, i.e., one person has information that another needs, and (2) both individuals involved in the resource exchange recognize the value of the relationship. Therefore, a relationship is more likely to form between two team members when there is a sufficient potential for exchange. Additionally, there is an implication that people view relations that minimize their dependence on others and improve their own power or position in the network as having high value (Settoon et al. 1996). Under the information processing view of construction projects, information is a resource being shared and exchanged across disciplines. Thus, exchange theories have value in explaining how communication ties develop among team members on construction projects.

\section{Role of Project Delivery Systems}

As construction operations become more complex, they will continue to shift away from the idea of a general contractor and, instead, engage a series of specialties that create a "quasi-firm" as described by Eccles (1981). Project delivery systems are, in effect, a quasi-firm arrangement that provide formality and consistency in the project organization. By necessity, most practitioners are familiar with the standard contract language, procurement procedures and typical lines of communication common in various delivery systems. However, not all project delivery systems are equally structured to allow for the fast information exchanges and effective communications demanded by an increasing fragmented industry. This is evidenced in the multiple empirical studies on project delivery systems that cite communication as an antecedent to project success. Beginning with Konchar and Sanvido's (1998) study, strong team communication found on Design-Build projects was identified as a predictor of both construction and delivery speed. While not specific to a single delivery system, Sambasivan and Soon (2007) similarly noted that a lack of communication between team members was a primary contributor to project delays. Asmar et al. (2013) found significantly lower RFI processing times and fewer resubmittals on Integrated Project Delivery (IPD) and "IPD-ish" projects, when compared to DesignBid-Build (DBB) and Construction Manager at Risk (CMR). Most recently, Franz et al. (2017) demonstrate that timely communication is reflective of the cohesiveness of the team and is a significant contributor to cost and quality outcomes. Communication was improved when the primary contractor and select specialty trades were involved early in the design process. Therefore, the project delivery system provides important context for how AEC teams exchange information and develop their communication networks.

\section{Conceptual Framework}

Aggregating these concepts and adding a dimension of time, we propose the conceptual framework shown in Figure 2. This is a dynamic framework, the purpose of which is to understand the impact of resilient communication on project performance. Within the framework, we identify 
Figure 2: Conceptual framework

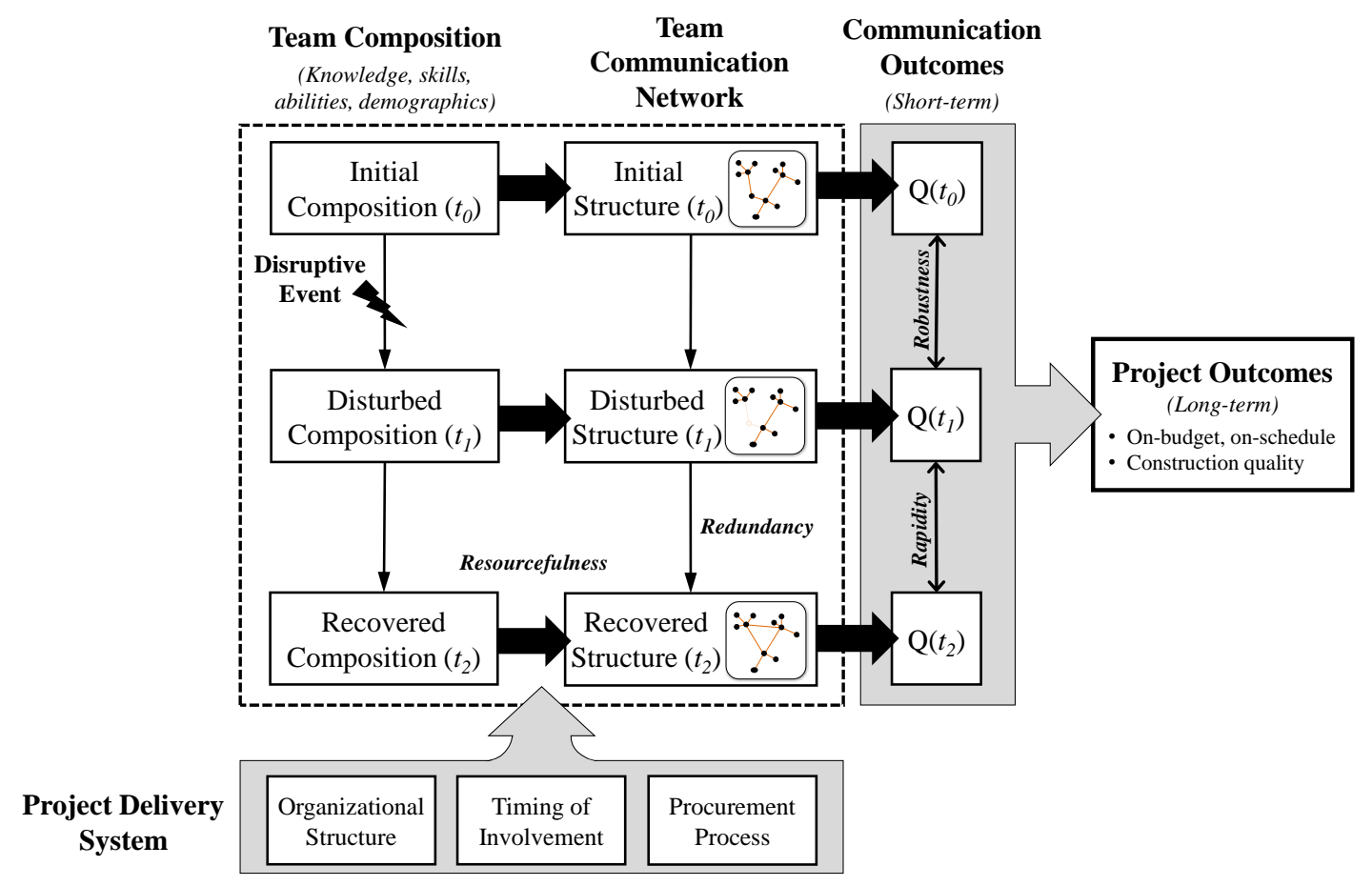

three antecedents that influence the structure of communication networks over time: (1) the contractual arrangements of the project delivery system that formalize roles and expectations for organizations and individuals, (2) the composition of the AEC team, including their available collective knowledge, skills and abilities, as well as the demographic attributes of individual members such as age, gender, education, and tenure in the industry, and (3) the severity and timing a disruptive compositional or role change event. These antecedents influence the structure of the network over three distinct time periods-predisruption, recovery and post-disruption-during which the team produces measurable communication outcomes that may be used to assess the resilience of their network to a given disruptive event. In alignment with aforementioned research (Bruneau et al. 2003, Cimellaro et al. 2010), we describe resilience across four dimensions: (a) rapidity of network recovery to pre-disruption levels of communication, (b) robustness of the network to retain a minimum level of communication following a change event, (c) redundancy of roles and structure in the network, and (d) the resourcefulness of individuals to assume new roles or form new ties. Lastly, the interaction of these properties is considered as an antecedent to longterm project outcomes, such cost and schedule performance. Long-term project outcomes are universally measured through the AEC team's ability to mitigate the 'iron triangle' (Atkinson, 1999) in which a team must deliver a quality product, on-schedule and within budget. However, as owners continue to place greater emphasis on lifecycle value of their projects, the concept of long-term outcomes can be extended to include sustainability, operations and maintenance, and facility flexibility.

Existing research on resilience in communication networks has several limitations, which this framework strives to overcome. First, many network studies in engineering use only cross-sectional methodologies that do not consider the process by which the networks evolve over time. These studies tend to assume that network structures are relatively stable in the long-term, which discounts the considerable, short-term changes in ties and node involvement often found 
in practice (Kossinets and Watts 2006). However, over the past two decades, there has been an increasing emphasis on longitudinal methods, specifically in the fields of organizational behavior and team science, to understand network evolution. These types of studies reveal new insights about many types of networks, including coordination networks following hazard events (Opdyke et al. 2016). Second, few studies adequately define and operationalize resilience outside of civil, infrastructure and other types of physical systems. The concept of resilience in physical systems is well-established, where performance can be expressed as a percentage of their static design capacity (e.g. kilowatts generated, customers served) at any given time. In physical systems, resilience to a disruptive event is thus mathematically defined as the normalized integral of the performance function taken between the time of the event and the time of full system recovery (Bruneau et al. 2003). However, for social systems with dynamic capacities, such as the communication networks found in AEC project teams, performance must be expressed and measured differently to derive a meaningful operationalization of resilience. Lastly, prior research does not focus on identifying the underlying mechanisms of action, such as the information processing process, for how resilience in communication networks lead to desirable project outcomes.

\section{Research Methods}

To demonstrate how this framework may be leveraged to study AEC project teams, we partnered with a large U.S. construction management firm. This firm performs work nationwide and, in 2016, put approximately \$4billion of work-in-place. At our request, they provided one month of communication data for an ongoing project. Specifically, we collected information on the correspondence being exchanged among team members by looking at email server logs. These logs are created and maintained on an organization's email server and keep track of incoming and outgoing messages. A single log entry includes all the data necessary to identify directed network nodes and ties: a timestamp (DD/MM/YY, HH:MM:SS), the email subject line, the sender's email address and the receiver's email address. We worked alongside the IT department of the construction management firm to extract only those logged messages that were exchanged between team members on the project. This process avoided the collection of unrelated or potentially sensitive email data. The result was a large text (.txt) file for the project, documenting the history of all emails exchanged within the team over a period of one month.

Previous research has proven the effectiveness of using email records to model and analyze communication networks (Kossinets and Watts 2006, 2009). Alternate methods of collecting network data, such as surveys, are more vulnerable to reporting bias, as well as respondent fatigue (Quintane and Kleinbaum 2011), especially on longer duration projects. Our decision to use email records to begin modeling communication is based on the state-of-practice on most construction projects. Since AEC project teams are rarely colocated at all times, they work primarily from their home offices or the project jobsite and typically meet in-person weekly or bi-weekly. This means that most project teams heavily rely on email to share information, coordinate activities and resolve conflicts. In addition, due to the fragmented nature of the AEC industry, these serve as formal communications that are commonly relied upon as historical documentation in case of legal disputes at project completion. We confirmed with members of the project team that email is the predominant medium of communication, and that text messages, phone conversations or face-to-face meetings were at a minimum for formal information exchange. To demonstrate the suitability of email data as a means of exploring our framework, we also employed content analysis of email subject lines. The objective of this analysis is to reveal how email is used by project teams and to identify cyclic, or recurring, communication patterns.

Email data was collected for a one-month period between March 9, 2017 and April 5, 2017. This period was of special interest, since early in the month, the onsite Project Engineer made a career move and left the project team suddenly. The Project Engineer's spouse was also staffed on the project as a Field Coordinator and left the team 
Figure 3: Periods of communication studies

\begin{tabular}{|c|c|c|c|c|c|c|c|}
\hline \multicolumn{7}{|c|}{ March 2017} & \multirow{8}{*}{$\begin{array}{l}\text { Week 1: March 9-15, } 2017 \\
\text { Compositional change on March 15th } \\
\text { Week 2: March 16-22, } 2017 \\
\text { Week 3: March 23-29, } 2017 \\
\text { Week 4: March 30-April 5, } 2017\end{array}$} \\
\hline \multicolumn{7}{|c|}{$\mathrm{Su}$ M Tu W Th F $\mathrm{Sa}$} & \\
\hline & & & 1 & 2 & 3 & 4 & \\
\hline 5 & 6 & 7 & 8 & 9 & 10 & 11 & \\
\hline 12 & 13 & 14 & 15 & 16 & 17 & 18 & \\
\hline 19 & 20 & 21 & 22 & 23 & 24 & 25 & \\
\hline 26 & 27 & 28 & 29 & 30 & 31 & 1 & \\
\hline 2 & 3 & 4 & 5 & & & & \\
\hline
\end{tabular}

two weeks later. To observe the impact of these compositional changes, the email data was separated into four, one-week periods (see Figure $3)$. These periods were not defined as a typical Monday through Friday workweek. Instead, they were arranged around when the compositional change occurred. Thus, Week 1 started on March 9, 2017 and ended on March 15, 2017, the project engineer's last day assigned to the project. Weeks 2, 3 and 4 were then added in seven-day increments. This choice in aggregation was made to increase the likelihood of detecting structural changes in the network due to the change in team membership. Within each period, the email data was used to create directed communication networks, where the number of email messages received or sent within each week defined the tie strengths in each adjacency matrix.

We then calculated cohesion measures for the structure of each week's communication network, including density, average degree and the centralization index. For a directed network, density is a measure of the average tie strength, calculated as the total of all tie values divided by the number of possible ties. Average degree is the average number of ties per node in the network. Both density and average degree consider the connectedness of the network, with higher values suggesting a more connected team. Lastly, the centralization index measures the variability in the degrees of nodes in the observed network as a percentage of degrees in a star-shaped network of the same size. Centralization, in this case, provides insight into the amount of variation in the communication network, with higher values suggesting that centrality varies substantively by team member and that certain individuals have positional advantages in the network. The cohesion measures were plotted over time to observe network-level effects. We also examined the centrality (in-degree and outdegree) and betweeness centrality of individual nodes each week. In-degree centrality represents the number of emails received, while out-degree centrality corresponds to the number of emails sent by a team member. Betweenness centrality is the extent to which an individual falls on paths between other pairs of team members in the network. An individual with a high betweenness means that more people depend on them to make connections or share information with others. The network analysis and graph visualizations were performed with UCINET and NetDraw, respectively.

\section{Results}

\section{Content Analysis}

Prior to forming the communication networks, a content analysis was performed on the email subject lines to offer some insight into the data set. Content types were adapted from Dabbish et al. (2005) and included: action requests, status updates, requests for information with and without a file attachment, work coordination, social, and "other" (e.g., missing or vague subject line). Each of these content types was considered mutually exclusive - that is, each email was coded to a single category. All messages in a single email thread, including the original, replies (RE:) and forwards (FW:) were considered as unique messages. Figure 4 provides a week-by-week distribution of emails by content type.

Information requests carrying a file attachment were the most common correspondence, confirming the importance of email as a tool for sharing and managing project information for this project team. However, certain content increased or decreased in volume, depending on the week. There is an increase in status update correspondence in Week 4 (March 30-April 5, 2017), as the new month begins, and the project team may be preparing for the new month's schedule update. Social and "other" messages drop 
Figure 4: Distribution of message title content by week

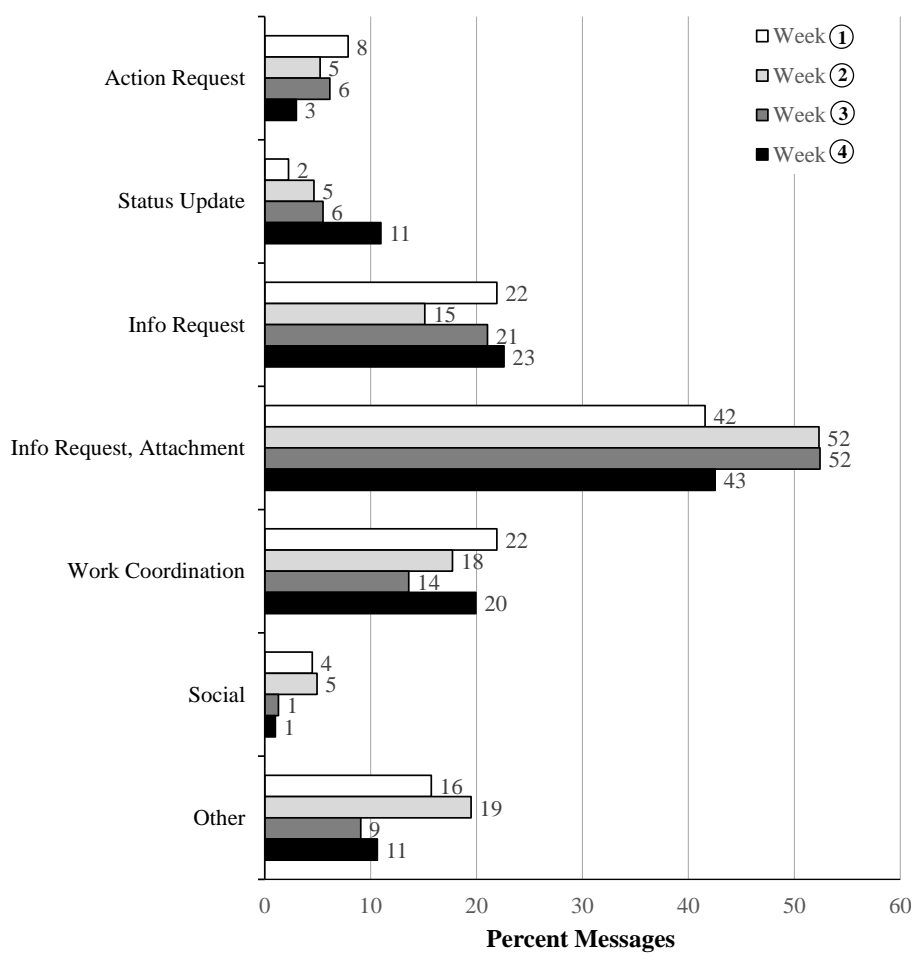

dramatically in Weeks 3 and 4, which coincides with the period immediately following the Project Engineer's departure. Although not visible in Figure 4, we also observed cyclic communication trends in subject lines within each content type. For example, there was an increase in emails, classified as information requests with attachments that contain financial or cost-related subject lines during Week 2 (March 16-22, 2017), which may align with the timing of preparing the monthly payment application. Similarly, there was a series of information requests during Week 1 related to required reporting of women and minority owned business activities that were not found in any other week. The data in this study was limited only one month; however, for longer duration projects, we recommend that these cyclic communications be controlled by baselining the number of weekly emails against the mean and standard deviation of all similar weeks in the data set.

\section{Network Analysis}

For the month of email data collection, network-level cohesion measures and graph visualizations for each week are shown in Figure 5. For each graph, the node size was set to represent betweenness centrality to better illustrate each team member's role in the flow of information. The position of nodes of each graph was determined using multidimensional scaling (MDS), which positions nodes that are strongly connected near each other, while weakly connected nodes are farther apart. Additionally, a summary of nodelevel in- and out-degree centrality and betweenness centrality measures for each team member is provided in Table 1.

At the time when the email communication data was generated, the project had entered the construction phase and was beginning the erection of the steel superstructure. We considered Week 1 as a representation of the pre-disruption state of the communication network. In this state, the network had a density of 0.611 , an average degree of 4.889 and a centralization index of 0.400 . The network is highly centralized around both the Project Engineer and Project Manager, but also has very connected periphery nodes. At the node-level, the Project Engineer had the highest betweenness 
Figure 5: Communication network evolution over observational period. Graph labels correspond to team member roles: $\mathrm{PX}=$ Project Executive, $\mathrm{PM}=$ Project Manager, $\mathrm{PE}=$ Project Engineer, $\mathrm{S}=$ Superintendent, $\mathrm{PC}=$ Project Coordinator, $\mathrm{BC}=\mathrm{BIM}$ Coordinator, $\mathrm{LC}=$ Lean Consultant, $\mathrm{AA}=$ Administrative Assistant, IN = Intern.
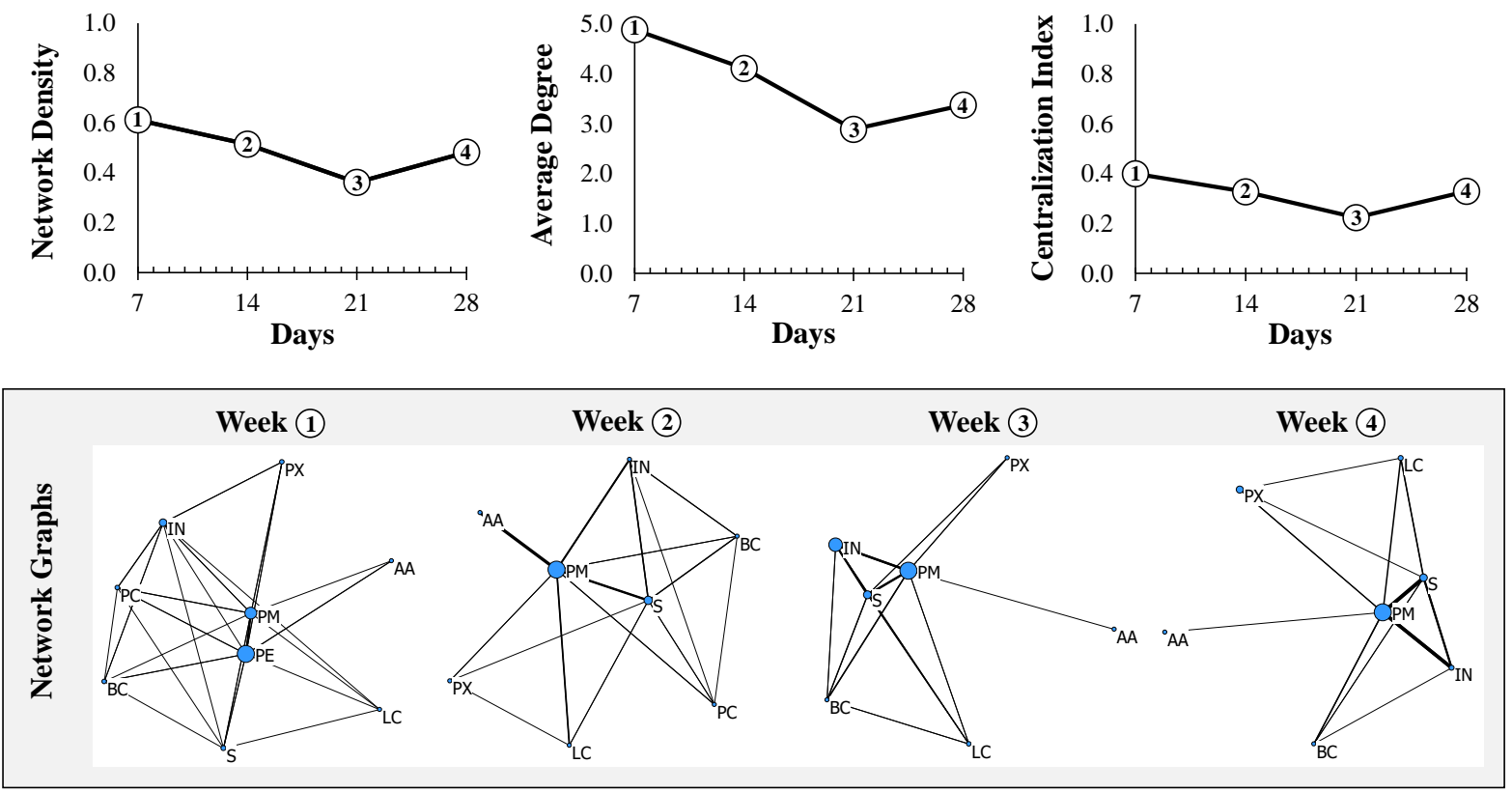

Table 1: Team member centrality and betweenness measures by week

\begin{tabular}{|c|c|c|c|c|c|c|c|c|c|c|c|c|}
\hline \multirow[b]{3}{*}{ Team Members } & \multicolumn{8}{|c|}{ Centrality } & \multirow{2}{*}{\multicolumn{4}{|c|}{ Betweenness Centrality }} \\
\hline & \multicolumn{4}{|c|}{ Out-degree } & \multicolumn{4}{|c|}{ In-degree } & & & & \\
\hline & $\begin{array}{c}\text { Week } \\
\text { (1) }\end{array}$ & $\begin{array}{c}\text { Week } \\
\text { (2) }\end{array}$ & $\begin{array}{c}\text { Week } \\
\text { (3) }\end{array}$ & $\begin{array}{c}\text { Week } \\
\text { (4) }\end{array}$ & $\begin{array}{c}\text { Week } \\
\text { (1) }\end{array}$ & $\begin{array}{c}\text { Week } \\
\text { (2) }\end{array}$ & $\begin{array}{c}\text { Week } \\
\text { (3) }\end{array}$ & $\begin{array}{c}\text { Week } \\
\text { (4) }\end{array}$ & $\begin{array}{c}\text { Week } \\
\text { (1) }\end{array}$ & $\begin{array}{c}\text { Week } \\
\text { (2) }\end{array}$ & $\begin{array}{c}\text { Week } \\
\text { (3) }\end{array}$ & $\begin{array}{c}\text { Week } \\
\text { (4) }\end{array}$ \\
\hline Project Manager & 7 & 7 & 5 & 6 & 7 & 7 & 7 & 6 & 5.9 & 13.0 & 11.3 & 10.2 \\
\hline Superintendent & 7 & 7 & 6 & 5 & 6 & 6 & 5 & 4 & 2.4 & 8.6 & 3.9 & 2.3 \\
\hline Project Engineer & 7 & -- & -- & -- & 8 & -- & -- & -- & 17.5 & -- & -- & -- \\
\hline Field Coordinator & 5 & 4 & 0 & -- & 4 & 3 & 1 & -- & 0.4 & 0.0 & 0.0 & -- \\
\hline Project Executive & 4 & 4 & 3 & 2 & 4 & 4 & 4 & 4 & 0.4 & 2.1 & 1.0 & 0.5 \\
\hline BIM Coordinator & 4 & 5 & 4 & 3 & 5 & 4 & 5 & 3 & 0.4 & 1.4 & 1.3 & 0.0 \\
\hline Lean Consultant & 1 & 4 & 0 & 5 & 4 & 5 & 0 & 3 & 0.0 & 3.9 & 0.0 & 1.8 \\
\hline Administrative Assistant & 2 & 3 & 1 & 2 & 1 & 2 & 1 & 0 & 0.0 & 0.0 & 0.0 & 0.0 \\
\hline Intern & 7 & 3 & 7 & 4 & 5 & 4 & 4 & 4 & 2.0 & 0.0 & 13.3 & 1.2 \\
\hline Average & 4.9 & 4.6 & 3.3 & 3.9 & 4.9 & 4.4 & 3.4 & 3.4 & 3.2 & 3.6 & 3.9 & 2.3 \\
\hline
\end{tabular}

centrality of all team members (17.5), followed more distantly by the Project Manager (5.9) and Superintendent (2.4). In- and out-degree centrality are nearly balanced for each team member, except for the Lean Consultant, who is not engaged in day- to-day project activities and mainly being copied on status updates. After the Project Engineer's departure on Day 7, a measurable disruption in the network structure was observed in Weeks 2 and 3. Density (0.514 in Week 2, 0.361 in Week 3), 
average degree (4.111 in Week 2, 2.889 in Week 3) and centralization (0.327 in Week 2, 0.224 in Week 3 ) all decrease, as the remaining team members shuffle their roles and responsibilities to compensate. The Project Manager, Superintendent and Intern all experience a sudden increase in their betweenness centrality to help bridge the network, and in- and out-degree centrality become more unbalanced. We see the communication network beginning to recover during Week 4, as density increases to 0.482 , average degree to 3.375 and centralization to 0.329 . At this point, the Project Manager has assumed a more prominent central and between position in the network, with the remaining team members returning to their predisruption node measures. While representing only four weeks of email data, further data extending into the following months would be necessary to determine if this represents a new equilibrium state.

\section{Discussion}

Using one month of email data, we observed a pattern of loss and recovery in network-level cohesion following an unplanned turnover in a construction manager's project team. This pattern resembles the resilience triangle theory advanced by Bruneau (2003). While additional data is needed to determine if the network topography itself is representative of its performance (i.e., effectiveness of communication), we can make several observations. First, there is evidence that betweenness centrality has an inversely proportional relationship to the robustness of the network. Prior to his departure, the Project Engineer had a betweenness centrality over three times greater than the Project Manager, who had the next highest betweennness centrality. Both were the longest standing members of the team and were involved prior to the design phase. Because of their history with the project, it was unsurprising to see them in such central network roles. However, their positions also created vulnerability in the team's communication network. After the Project Engineer's departure, information being exchanged via email decreased on a per team member basis, resulting in a nearly $50 \%$ reduction in network density and $40 \%$ reduction in average degree at their lowest points. This was a significant change in network connectivity, suggesting that the network was not very robust.

Second, in-degree and out-degree centrality of team members provided insight into the network's redundancy. While active on the project, the Project Engineer had the highest in-degree centrality, making him the most prominent member of the team, in terms of managing project team correspondence and information exchange. Other team members were accustomed to funneling information through this individual, which likely led to some confusion in where to send information after his departure. On the other hand, in terms of out-degree centrality, several team members shared similar positions in the network. The Project Manager, Superintendent and Intern were all highly influential and consistently dispersed a large amount of information to the team even after the Project Engineer's departure. This suggests a level of redundancy in the network that may have either lessened the impact of losing the Project Engineer or allowed the team to recover more rapidly.

Lastly, while the network methodology was useful in quantifying and visualizing the effect of turnover within a project team, the communication data itself cannot explain why the network topography changed the way that it did in this case. We have speculated about team member roles relative to their network positions, but prior research shows that other conditions, such as homophily, affect network evolution. This project team was somewhat diverse. Approximately $1 / 3$ of the members were women, one member was an international student that eventually became fulltime, and all members started their careers in very different geographic regions across the U.S. Greater diversity is theorized to create fault lines in communication networks, which would slow the recovery process following a disruption. This project team's communication pattern did not appear to vary by the demographics of individual members, which suggests that the team was either too small or not diverse enough along particular axes to form fault lines. The project delivery method almost certainly had an effect as well, although we cannot parse out specific effects from a single case. With an IPD approach, relationships among team members are more complex compared to traditional delivery methods, which have simpler and more clearly defined hierarchical structures. 
This complexity may have both advantages and disadvantages with respect to communication network resilience. For example, less role rigidity can empower individual team members to sidestep organizational boundaries and temporarily fulfill the duties of a departed member. For teams that were formed during the early phases of design and have remained together, the network is more likely to have high connectivity and therefore redundancy in information pathways. On the other hand, the more rigid role structure found in design-bid-build or construction manager at risk delivery methods may provide needed stability during a disruption. If there is turnover in the team, these delivery methods have less ambiguity in individual roles and responsibilities and can allow a team to quickly work around the departed member, provided that the turnover does not occur in one of the more central or prominent roles, such as the Project Manager.

Resilience in AEC project teams has the potential to improve performance at the projectand firm-levels. As a first step in more thoughtful organizational design, the framework presented in this paper provides a structured approach for determining the resilience (in terms of robustness, rapidity, resourcefulness and redundancy) of communication networks, which serve as pathways of information exchange on a project. Additionally, the framework seeks to incorporate the roles and contribution of individuals within AEC project teams to the overall success of the design and construction process. By examining the underlying theories and our initial findings, we see the following potential implications of studying resilience in AEC project teams:

Project-level. The most direct influence, relative to the research framework, is an approach for recognizing and potentially forecasting the impact of personnel movement and turnover on both team communications in the short-term and project performance (e.g., cost and schedule) in the long-term. The operational disruptions of midproject changes in personnel are well-known to the AEC industry. Because of the interdependence of tasks on construction and engineering projects, the loss of a team member may affect the ability of others to perform their work efficiently or effectively. If the lost team member is highly connected and central to the team's communication network, the entire project may be delayed. However, the impact of the loss is not random. As suggested by our framework, communication outcomes can be considered as a function of the network structure over time, team composition, and characteristics of the project delivery system. Thus, there are implications for tracking and forecasting performance based on how a communication network evolves. In practical terms, these outcomes could be taken as percent plan complete (PPC) measures from the use of the Last Planner System or response latency for RFIs and submittals. Both measures would be indicative of the effectiveness of the team's communication. While beyond the scope of our sample data collection, understanding how communication outcomes change, as a function of network structure, will allow assessment of resilience in AEC project teams. The predictive capacity offered by this framework can make project teams more agile in responding to both internal and external disruptions. For example, we can better understand the attributes and role structures needed to replace a departing team member to maintain network functionality, or we can consider big data analysis of communication network vulnerabilities, such as the identification of overly connected team members whose departure would increase the risk of project failure. Even on projects without turnover, a better understanding the factors that create more consistent and reliable communication can generally improve the work flow, coordination and efficiency of information exchanges on complex, construction and engineering projects.

Firm-level. Beyond the value of structuring more resilient team communication on a single project, the concept of resilient project networks also benefits firms. Even if the effects of having high resilience to turnover may be small on the project-level, they would be compounded across the number of projects managed by typical construction management firms. An understanding of the consequences of team disruptions would allow firm executives to make more informed personnel assignments and reduce the unnecessary transfer of personnel between projects, or better transition planning if the person in question is central to the project's communication structure. Some firms may even choose to hire individuals with a multiplicity of skills that can create 
redundancy in project teams and reduce the potential communication breakdown caused by losing a team member. Similarly, firms may begin considering more specific attributes related to resourcefulness of personnel as desirable hiring criteria. These strategies enable a leaner organization that incorporates flexible capacity in its human resources. As illustrated in the PM 2.0 article by Levitt (2011), the paradigm of project management is evolving rapidly to address new challenges. Growing trends in mega-projects could be considered in terms of an organization's resilience in their ability to engage and inform stakeholders, creating redundant channels for timely communication, and rapidity of recovery within task groups or cross-functional teams that make up sub-groups of the overall organization. Similarly, the mapping of communication channels for mixed organizations, such as public-privatepartnerships, could identify challenges resulting from elections or changes in leadership.

\section{Conclusions}

This paper presents a framework that considers the resilience of communication networks, chosen because of the importance of information exchange to engineering project success. By incorporating theories of resilience from civil engineering, network formation from organizational science, and project delivery systems from the construction industry, the framework offers a holistic view of the impact of compositional change in project teams over time. Team composition influences the communication network structure, which conveys resilience to disruption that influence project outcomes (e.g. budget and schedule). A portion of this framework was tested on an in-progress construction project, using one month of email data to model the construction management team's communication network. The resulting longitudinal networks illustrated that measurable short-term changes in network cohesion, suggestive of the resilience triangle, were observable after the Project Engineer's abrupt departure. Specifically, we observed between 40$50 \%$ decreases in density, average degree and degree centralization at the network-level in the two weeks following the disruption. At the nodelevel, the Project Engineer had a high betweenness centrality relative to other members, which is, likely, what made the network more vulnerable to his departure. After his departure, the remaining team members adjusted their communication patterns and we observed a rebound in network cohesion during the final week of the data collection period. The high out-degree centrality of the three most influential team members (Project Manager, Superintendent and Intern) suggested some redundancy in the network that may have enabled this rapid recovery.

Despite our progress in defining and framing the problem, we are a long way from understanding the antecedents and long-term benefits of more resilient communication networks, specifically in the unique setting of construction projects. Further study is needed to determine the role that surfaceand deep-level demographics of the team members, as well as variations in the project delivery system, play in shaping the structure of communication networks over time. Similarly, the short-term performance of the network must be assessed regularly by using measures of communication effectiveness that are both relevant to the project team and reliable for research. These measures will ultimately allow for a meaningful operationalization of resilience within a project organization. Drawing on analogs from physical systems, resilience in social systems has the potential to improve the performance of AEC project teams by minimizing the negative consequences of personnel changes and turnover that occur with regularity in the construction industry.

\section{References}

Balkundi, P., Kilduff, M., Barsness, Z. I., \& Michael, J. H. (2007). Demographic antecedents and performance consequences of structural holes in work teams. Journal of Organizational Behavior, 28(2), 241-260.

Benson, J. K. (1975). The interorganizational network as a political economy. Administrative science quarterly, 229-249.

Berggren, C. Soderlund, J. and Anderson, C. (2001). Clients, contractors, and consultants: the consequences of organizational fragmentation in contemporary project environments. Project Management Journal, 32(3), 39-48. 
Bowen, P. A., and Edwards, P. J. (1996). Interpersonal communication in cost planning during the building design phase. Construction Management \& Economics, 14(5), 395-404.

Briscoe, G. (2005). Women and minority groups in UK construction: recent trends. Construction Management and Economics, 23(10), 1001-1005.

Bruneau, M., Chang, S. E., Eguchi, R. T., Lee, G. C., O'Rourke, T. D., Reinhorn, A. M., Shinozuka, M., Tierney, K., Wallace, W.A. and von Winterfeldt, D. (2003). A framework to quantitatively assess and enhance the seismic resilience of communities. Earthquake Spectra, 19(4), 733-752.

Bunderson, J. S., and Sutcliffe, K. M. (2002). Comparing alternative conceptualizations of functional diversity in management teams: Process and performance effects. Academy of management journal, 45(5), 875-893.

Butts, C. T. (2009). Revisiting the foundations of network analysis. Science, 325(5939), 414-416.

Cherns, A. and Bryant, D. (1983). Studying the client's role in construction management. Construction Management and Economics, 2(2), 177-184.

Chinowsky, P., Diekmann, J., and Galotti, V. (2008). Social network model of construction. Journal of construction engineering and management, 134(10), 804-812.

Chan, A., Chan, D., Fan, L., Lam, P. and Yeung, F. (2005). Partnering for construction excellence - a reality or myth? Building and Environment, 41(12), 1924-1933.

Chua, D. K. H., Kog, Y. C., and Loh, P. K. (1999). Critical success factors for different project objectives. Journal of construction engineering and management, 125(3), 142-150.

Cimellaro, G. P., Reinhorn, A. M., and Bruneau, M. (2010). Framework for analytical quantification of disaster resilience. Engineering Structures, 32(11), 3639-3649.

Cummings, J. N., and Cross, R. (2003). Structural properties of work groups and their consequences for performance. Social networks, 25(3), 197-210.

Dabbish, L., Kraut, R., Fussell, S. and Kiesler, S. (2005). Understanding email use: Predicting action on a message. In proceedings of CHI'05. ACM, New York, 431-440.

Dainty, A. R., Millett, S. J., and Briscoe, G. H. (2001). New perspectives on construction supply chain integration. Supply chain management: An international journal, 6(4), 163-173.

Devine, D.J., and Philips, J.L. (2001). Do smart teams do better: A meta-analysis of cognitive ability and team performance. Small Group Research, 32: 507532.

Di Marco, M. K., and Taylor, J. E. (2011). The impact of cultural boundary spanners on global project network performance. The Engineering Project Organization Journal, 1(1), 27-39.

Duyshart, B. Walker, D., Mohamed, S. and Hampson, K. (2003). An example of developing a business model for information and communication technologies (ICT) adoption on construction projects - the National Museum of Australia project. Engineering, Construction, and Architectural Management, 10(3), 179-192.

Eccles, R.G. (1981). The quasifirms in the construction industry. Journal of Economic Behavior and Organization (2), 335-357.

Egan, J. (1998). Rethinking Construction, London: DETR/Stationery Office.

El Asmar, M., Hanna, A. S., and Loh, W. Y. (2013). Quantifying performance for the integrated project delivery system as compared to established delivery systems. Journal of Construction Engineering and Management, 139(11), 04013012.

Franz, B., Leicht, R., Molenaar, K. and Messner, J. (2017). Impact of team integration and group cohesion on project delivery performance. Journal of Construction Engineering and Management, DOI: 10.1061/(ASCE)CO.1943-7862.0001219.

Gajendran, T. and Brewer, G. (2007). Integration of information and communication technology influence of the cultural environment. Engineering, Construction, and Architectural Management, 14(6), 532-549.

Gunderson, L. H. (2000). Ecological resilience--in theory and application. Annual review of ecology and systematics, 425-439.

Heider, F. (1958). The Psychology of Interpersonal Relations. New York: Wiley.

Henisz, W.J., Levitt, R.E. and Scott, R. (2012). Toward a unified theory of project governance: Economic, sociological and psychological supports for relational contracting. The Engineering Project Organizations Journal, 2(1-2), 37-55.

Horwitz, S. K., and Horwitz, I. B. (2007). The effects of team diversity on team outcomes: A meta-analytic review of team demography. Journal of management, 33(6), 987-1015.

Ireland, P. (2004). Managing appropriately in construction power regimes: understanding the impact of regularity in the project environment. Supply Chain Management, 9(5), 372-382.

Javernick-Will, A. N., and Scott, W. R. (2010). Who needs to know what? Institutional knowledge and 
The Engineering Project Organization Journal (December 2018) Volume 8

global projects. Journal of Construction Engineering and Management, 136(5), 546-557.

Jin, Y., and Levitt, R. E. (1996). The virtual design team: A computational model of project organizations. Computational \& Mathematical Organization Theory, 2(3), 171-195.

Konchar, M. and Sanvido, V. (1998). Comparison of US project delivery systems. Journal of Construction Engineering and Management, 124(6), 435-444.

Kossinets, G., and Watts, D. J. (2006). Empirical analysis of an evolving social network. Science, 311(5757), 88-90.

Kossinets, G., and Watts, D. J. (2009). Origins of homophily in an evolving social network. American Journal of Sociology, 115(2), 405-450.

Lahdenperä, P. (2012). Making sense of the multi-party contractual arrangements of project partnering, project alliancing and integrated project delivery. Construction Management and Economics, 30(1), 57-79.

Larson, A. (1992). Network dyads in entrepreneurial settings: a study of the governance of exchange relationships. Administrative Science Quarterly, Vol. 37, pp.76-104.

Latham, S. M. (1994). Constructing the Team. London: HM Stationery Office.

Lau, D. C., and Murnighan, J. K. (1998). Demographic diversity and faultlines: The compositional dynamics of organizational groups. Academy of Management Review, 23(2), 325-340.

Lee, S., Nikolic, D., and Messner, J.I. (2014). Framework of the Virtual Construction Simulator 3 for Construction Planning and Management Education, Journal of Computing in Civil Engineering, 29(2): 05014008.

Macomber, H., and Howell, G. (2003). Linguistic action: Contributing to the theory of lean construction. In Proceedings of the 11th Annual Meeting of the International Group for Lean Construction (pp. 1-10).

Manyena, S. B. (2006). The concept of resilience revisited. Disasters, 30(4), 434-450.

Masten, A. S. (2001). Ordinary magic: Resilience processes in development. American Psychologist, 56, 227.

McCarty, C., Molina, J. L., Aguilar, C. and Rota, L. (2007). A comparison of social network mapping and personal network visualization. Field Methods, 19:145-162.

McPherson, J. M., and Smith-Lovin, L. (1987). Homophily in voluntary organizations: Status distance and the composition of face-to-face groups. American Sociological Review, 370-379.

Menches, C. L., and Abraham, D. M. (2007). Women in construction - tapping the untapped resource to meet future demands. Journal of Construction Engineering and Management, 133(9), 701-707.

Mizruchi, M. S. (1996). What do interlocks do? An analysis, critique, and assessment of research on interlocking directorates. Annual Review of Sociology, 271-298.

Molina, J. L.,Maya-Jariego, I. and McCarty, C. (2014) Giving Meaning to Social Networks: Methodology for Conducting and Analyzing Interviews based on Personal Network Visualizations. In Mixed Methods Social Networks Research: Design and Applications (Structural Analysis in the Social Sciences). Betina Hollstein and Silvia Dominguez, eds. Cambridge University Press.

Mollaoglu-Korkmaz, S., Swarup, L., and Riley, D. (2011). Delivering sustainable, high-performance buildings: Influence of project delivery methods on integration and project outcomes. Journal of Management in Engineering, 29(1), 71-78.

Monge, P. R., and Contractor, N. (2003). Theories of Communication Networks. New York: Oxford University Press

Newman, M. E., Forrest, S., and Balthrop, J. (2002). Email networks and the spread of computer viruses. Physical Review E, 66(3), 035101.

Nikolic, D., Lee, S., Zappe, S.E., and Messner, J.I. (2015). Integrating Simulation Games into Construction Curricula-The VCS3 Case Study, International Journal of Engineering Education, 31(6), pp. 1661-1677.

Park, J., Seager, T. P., Rao, P. S. C., Convertino, M., and Linkov, I. (2013). Integrating risk and resilience approaches to catastrophe management in engineering systems. Risk Analysis, 33(3), 356-367.

Parker, S. K., and Skitmore, M. (2005). Project management turnover: causes and effects on project performance. International Journal of Project Management, 23(3), 205-214.

Phua, F. T., and Rowlinson, S. (2004). How important is cooperation to construction project success? A grounded empirical quantification. Engineering, Construction and Architectural Management, 11(1), 45-54.

Provan, K. G., and Milward, H. B. (1995). A preliminary theory of interorganizational network effectiveness: A comparative study of four community mental health systems. Administrative science quarterly, 133.

Quinn R.E. and Cameron, K.S. (eds). (1988). Paradox and Transformation: toward a theory of change in 
The Engineering Project Organization Journal (December 2018) Volume 8

organizations and management, Ballinger Publishing Company, Cambridge, MA.

Quintane, E., and Kleinbaum, A. M. (2011). Matter over mind? E-mail data and the measurement of social networks. Connections, 31(1), 22-46.

Raiden, A. B., Dainty, A. R., and Neale, R. H. (2004). Current barriers and possible solutions to effective project team formation and deployment within a large construction organization. International Journal of Project Management, 22(4), 309-316.

Sambasivan, M. and Soon, Y. W. (2007). Causes and effects of delays in Malaysian construction industry. International Journal of project management, 25(5), 517-526.

Sasovova, Z., Mehra, A., Borgatti, S. P., and Schippers, M. C. (2010). Network churn: The effects of selfmonitoring personality on brokerage dynamics. Administrative Science Quarterly, 55(4), 639-670.

Settoon, R. P., Bennett, N., and Liden, R. C. (1996). Social exchange in organizations: Perceived organizational support, leader-member exchange, and employee reciprocity. Journal of Applied Psychology, 81(3), 219.

Shaw, J. D., Duffy, M. K., Johnson, J. L., \& Lockhart, D. E. (2005). Turnover, social capital losses, and performance. Academy of Management Journal, 48(4), 594-606.

Sherif, M. (1958). Superordinate goals in the reduction of inter-group conflicts. American Journal of Sociology, 63, 349-356.

Stevens, M. J., and Campion, M. A. (1999). Staffing work teams: Development and validation of a selection test for teamwork settings. Journal of Management, 25(2), 207-228.

Stewart, G. (2006). A meta-analytic review of relationships between team design features and team performance. Journal of Management, 32: 29-54.

Thietart, R. and Forgues, B. (1995). Chaos theory and organizations. Organization Science, 6(1), 19-31.

Walker, B., Holling, C. S., Carpenter, S. R., and Kinzig, A. (2004). Resilience, adaptability and transformability in social--ecological systems. Ecology and society, 9(2), 5.

Weick, K. E. (1977). Organization design; organization as self-designing systems. Organizational Dynamics, 6(2), 31-46.

Whitley, R. (2006). Project-based firms: new organizational form or variations on a theme? Industrial and Corporate Change, 15(1), 77-99.

Wolf, T., Schroter, A., Damian, D., and Nguyen, T. (2009, May). Predicting build failures using social network analysis on developer communication. In Proceedings of the 31st International Conference on
Software Engineering (pp. 1-11). IEEE Computer Society.

Youssef, C. M., and Luthans, F. (2007). Positive organizational behavior in the workplace the impact of hope, optimism, and resilience. Journal of Management, 33, 774-800.

Zaheer, A., \& Bell, G. G. (2005). Benefiting from network position: firm capabilities, structural holes, and performance. Strategic Management Journal, 26(9), 809-825. 